
8 Research Square
Preprints are preliminary reports that have not undergone peer review.
They should not be considered conclusive, used to inform clinical practice,
or referenced by the media as validated information.

\title{
Induction Therapy and Outcome of Proliferative Lupus Nephritis in the Top End of Northern Australia - A single centre study retrospective study
}

Chi Xu ( $\nabla$ chrixu@gmail.com )

Royal Darwin Hospital

Kim Ling Goh

Royal Darwin Hospital

Asanga Abeyaratne

Royal Darwin Hospital

Kelum Priyadarshana

Royal Darwin Hospital

\section{Research Article}

Keywords: Lupus nephritis, systemic lupus erythematosus, mycophenolate, Indigenous Australians, induction immunosuppression

Posted Date: September 28th, 2021

DOl: https://doi.org/10.21203/rs.3.rs-863150/v1

License: (c) (i) This work is licensed under a Creative Commons Attribution 4.0 International License. Read Full License 


\section{Abstract}

\section{Background}

Lupus nephritis is a common manifestation of Systemic Lupus Erythematosus. Mycophenolate is recommended by guidelines for induction therapy in patients with proliferative lupus nephritis and nephrotic range proteinuria Class $V$ lupus nephritis. Indigenous Australians suffer disproportionally from systemic lupus erythematosus compared to non-Indigenous Australians.

\section{Methods}

We retrospectively identified patients with newly diagnosed biopsy-proven class III lupus nephritis, class IV lupus nephritis and class V lupus nephritis with nephrotic range proteinuria from $1^{\text {st }}$ Jan 2010 to $31^{\text {st }}$ Dec 2019 in our institution and examined for the patterns of prescribed induction therapy and clinical outcome. The primary efficacy outcome of interest was the incidence of complete response (CR) and partial response (PR) at one-year post diagnosis as defined by the Kidney Disease: Improving Global Outcome (KDIGO) guideline. Secondary efficacy outcome was a composite of renal adverse outcome in the follow-up period. Adverse effect outcome of interest was any hospitalisations secondary to infections in the follow-up period. Continuous variables were compared using Student's t-test or Mann-Whitney Utest. Categorical variables were summarised using frequencies and percentages and assessed by Fisher's exact test. Time-to-event data was compared using the Kaplan-Meier method and Log-rank test. Count data were assessed using the Poisson's regression method and expressed as incident rate ratio.

\section{Results}

20 of the 23 patients included in the analysis were managed with mycophenolate induction upfront. Indigenous Australian patients ( $N=15)$, compared to non-Indigenous patients $(N=5)$ received lower cumulative dose of mycophenolate mofetil over the 24 weeks ( $375 \mathrm{~g}$ vs. $256 \mathrm{~g}, \mathrm{p}<0.05$ ), had a nonsignificant lower incidence of complete remission at 12 months ( $60 \%$ vs. $40 \%, p=0.617$ ), higher incidence of composite renal outcome ( $0 / 5$ patients vs. $5 / 15$ patients, $p=0.20)$ and higher incidence of infection related hospitalisations, (incident rate ratio $3.66,95 \%$ confidence interval $0.89-15.09, p=0.073$ ).

\section{Conclusion}

Mycophenolate as upfront induction in Indigenous Australian patients were associated with lower incidence of remission and higher incidence of adverse outcomes. These observations bring the safety and efficacy profile of mycophenolate in Indigenous Australians into question.

\section{Introduction}

Systemic lupus erythematosus (SLE) is a chronic multi system autoimmune disease that predominantly affects women of childbearing age. The disease often involves the kidneys with lupus nephritis (LN) occurring in approximately $50 \%$ of patients with SLE. ${ }^{1,2}$ Histologically, LN is classified into six classes 
depending on the glomerular pathology with proliferative LN divided to class III and class IV depending on whether the lesion is focal or diffused. Membranous LN is classified as class V LN. ${ }^{3}$ Proliferative lupus nephritis and membranous $L N$ with nephrotic range proteinuria are typically managed with a short and intensive induction phase treatment with systemic immunosuppression for 3 to 6 months. ${ }^{4-8}$

In addition to corticosteroids, large multicenter randomised control trials (RCT) had supported the routine use of intravenous and oral cyclophosphamide as well as mycophenolate mofetil (MMF) for induction. ${ }^{1,9-11}$ These had emerged as the standard of care for upfront induction therapy. Rituximab, the anti-CD20 monoclonal antibody, was typically reserved for relapsed or refractory cases. In the phase 3 Lupus Nephritis Assessment with Rituximab (LUNAR) trial, the addition of rituximab to standard of care failed to demonstrate any additional benefit when compared to standard of care alone, despite a statistically significant improvement in complement C3 and C4 levels and a reduction in anti-double stranded DNA (anti-dsDNA) titer.

Aboriginal and Torres Strait Islander Australians (hereto respectively referred to as Indigenous Australians) are the first nation people of Australia. They suffered from a disproportionally higher incidence and prevalence of SLE and LN compared to non-Indigenous Australians. ${ }^{12-15}$ Emerging evidence had suggested that SLE in Indigenous Australians could be pathologically distinct and manifest differently compared to SLE in non-Indigenous Australians. ${ }^{13,15-17}$ Currently, there are a paucity of data concerning the management of $L N$ in Indigenous Australian patients. Despite observable differences in phenotype and biochemical markers between Indigenous Australians and non-Indigenous Australians LN, induction treatment had largely been extrapolated from studies of international cohorts and comparative to that of non-Indigenous Australians. We therefore sought to investigate the pattern of prescription and outcome in LN patient cohort from the Top End of Northern Territory, Australia and see if there is a difference in outcome between Indigenous Australian patients and non-Indigenous patients.

The Top End is a geographical region located in the northern tip of Northern Territory. It encompasses an area approximately $245,000 \mathrm{~km} 2$ that includes the capital city Darwin, Kakadu National Park, Arnhem Land, and Katherine Region. The Top End Health Service has a catchment area that occupies $35 \%$ of total land area of NT and $81 \%$ of total NT population. $26 \%$ of residents in the TEHS catchment area are Indigenous Australians. ${ }^{18}$

\section{Methods}

We retrospectively identified all patients with newly diagnosed and biopsy proven class III LN, class IV LN and class V LN with nephrotic range proteinuria from 1st January 2010 to 31st December 2019 in our institution. We then examined the pattern of prescribed immunosuppression therapy and the subsequent outcome during the follow-up period of 1st January 2010 to 31st December 2019.

Patients were identified from existing renal biopsy database. The database contained all renal biopsies performed in our institution from 2007. Two independent renal anatomical pathologists from an 
interstate laboratory examined and reported all biopsy samples. Histological data were collected thereafter from authorized reports. A diagnosis of LN and International Society of Nephrology/Renal Pathology Society (ISN/RPS) classification were made on both histological features as well as the presence of classic 'full-house' pattern of immunofluorescence staining to $\lg G$, IgM, IgA, C3, C1q, Kappa and Lambda light chain. We included all patients $>18$ years of age with newly diagnosed class III, IV and/or nephrotic-range proteinuric class $\mathrm{V}$ for analysis. Nephrotic range proteinuria is defined by presence of $>3 \mathrm{~g}$ urinary protein over 24 hour collection. In cases where a 24 hour urine collection was unavailable, nephrotic range proteinuria was defined by a spot albumin-creatinine ratio (ACR) > $300 \mathrm{mg} / \mathrm{mmol}$. Patients were excluded if a history of LN was known prior to 1st January 2010.

The exposures of interest were the induction immunosuppression therapy received in the first 24 weeks since biopsy. Data were obtained from pharmacy record in our institution. Methylprednisolone, typically given in intravenous pulse therapy of $1 \mathrm{~g}$ repeated over 3 to 5 days, was recorded as a dichotomous variable. Cumulative prescribed dosages of oral prednisolone and MMF over the six months period were recorded and expressed as continuous variables. The MMF dose equivalent was recorded in patients that were prescribed mycophenolic acid (MPA), for example 360mg MPA were recorded as 500mg MMF and $720 \mathrm{mg}$ MPA was recorded as $1000 \mathrm{mg}$ MMF.

The primary efficacy outcome of interest was the incidence of CR and PR at one-year post diagnosis as defined by the Kidney Disease: Improving Global Outcome (KDIGO) guideline (See Table 1). Secondary efficacy outcome was a composite of renal adverse outcome consisting of relapse of disease as deemed by the treating clinician, doubling of serum creatinine for 3 months, end-stage kidney disease (ESKD) requiring dialysis for at least 12 sessions or death from any cause. This was recorded as time-to-event data. Time at risk was measured using patient-years (ptyr), with 1 patient-year defined as an at-risk period of 1 year for 1 patient. Adverse effect outcome of interest was any hospitalisations secondary to infections, recorded as count data. The infection diagnosis was defined and recorded according to the primary admission diagnosis on discharge summary. Admissions were not included in the analysis if an infectious cause was the secondary diagnosis. Patient ethnicity, including whether they self-identified as Aboriginal and Torres Strait Australians or non-Indigenous Australians was obtained from the registration questionnaire at the time of first presentation to our institution and recorded as a dichotomous variable. 


\section{Complete Decline in urine PCR to $\leq 0.5 \mathrm{~g} / \mathrm{g}(\leq 50 \mathrm{mg} / \mathrm{mmol})$; return of serum Cr previous baseline response (CR)}
Partial $>50 \%$ decrease in urine PCR; if there was nephrotic-range proteinuria, then reduction to < response $3,000 \mathrm{mg} / \mathrm{g}[<300 \mathrm{mg} / \mathrm{mmol}]$ AND; stabilization $( \pm 25 \%)$, or improvement of serum $\mathrm{Cr}$, (PR) but not to normal

No $\quad$ Failure to achieve CR or PR

response

PCR - protein-creatinine ratio, $\mathrm{Cr}$ - creatinine.

Continuous variables were assessed for normality. Continuous variables were summarised using mean and standard deviation and compared using Student's t-test if normally distributed; If not normally distributed, they were summarised using medians and interquartile ranges and compared using MannWhitney U-test. Categorical variables, including binary and ordinal outcomes, were summarised using frequencies and percentages and assessed by Fisher's exact test. Time-to-event data was assessed using the Kaplan-Meier method. Count data, including the number of hospitalisations was assessed using the Poisson's regression method and expressed as incident rate ratio. Statistical significance was defined by a two-tail p-value of $<0.05$. All statistical analyses were performed with Stata/IC16.0 software.

\section{Ethics approval}

was obtained from the Human Research Ethics Committees of the Menzies School of Research and the Top End Health Service Research Governance Office, Northern Territory, Australia (Reference number HREC-2020-3869)

\section{Results}

During the follow-up period, Thirty-one patients were diagnosed with class III/IV and nephrotic range class V LN. Eight patients were excluded as they had a prior diagnosis of lupus nephritis and treated previously. 23 newly diagnosed LN patients were included for the analysis.

Mycophenolate was the immunosuppression agent of choice in 20 of the 23 patients. Of the three remaining patients, all of whom were Indigenous Australians, one patient received four doses of intravenous $1 \mathrm{~g}$ rituximab (on day 1 and 8 followed by two additional doses six months later) by her treating rheumatologist and general medicine physician and remained in CR after 39months until the end of follow-up period. One patient was diagnosed with $L N$ in her first trimester of pregnancy and was treated with combination tacrolimus and azathioprine for 3 weeks before her care was transferred interstate. 1 patient was managed with prednisolone initially before becoming disengaged from our medical service and ultimately succumbed to E. coli bacteraemia two months later. No patients in our study received cyclophosphamide upfront. The baseline characteristics of the 20 patients who received 
mycophenolate induction therapy are listed in Table 2. At the time of diagnosis, a higher proportion of Indigenous Australian patients had co-morbidities including diabetes mellitus, hypertension and acute rheumatic fever/rheumatic heart disease, these were however, not statistically significant. The baseline serum creatinine was comparable between the two cohorts. While a higher pre-induction urine albumincreatinine ratio was observed in Indigenous Australian patients, this was not statistically significant.

Table 2

- Baseline characteristics of patients who received mycophenolate

\begin{tabular}{|c|c|c|c|}
\hline & $\begin{array}{l}\text { Non-Indigenous } \\
\text { Australians }(\mathrm{N}=5)\end{array}$ & $\begin{array}{l}\text { Indigenous Australians } \\
(\mathrm{N}=15)\end{array}$ & $\begin{array}{l}\mathrm{P} \text { - } \\
\text { value }\end{array}$ \\
\hline Age (mean+/-SD) & $36.4+/-6.50$ & $36.2+/-12.37$ & 0.97 \\
\hline Women, n (\%) & $3(60 \%)$ & $13(87 \%)$ & 0.20 \\
\hline Diabetes mellitus, n (\%) & 0 & $3(20 \%)$ & 0.28 \\
\hline Hypertension n (\%) & $2(20 \%)$ & $3(20 \%)$ & 0.37 \\
\hline $\begin{array}{l}\text { Acute rheumatic fever / rheumatic } \\
\text { heart disease }\end{array}$ & 0 & $4(27 \%)$ & 0.20 \\
\hline $\begin{array}{l}\text { Pre-induction creatinine } \\
\text { (micromol/L) }\end{array}$ & $73.2+/-12.0$ & $74.5+/-21.7$ & 0.90 \\
\hline Pre-induction ACR (g/mol) & $135.6+/-187.7$ & $341.1+/-338.32$ & 0.22 \\
\hline \multicolumn{4}{|l|}{ Pathological Classification } \\
\hline III & $1(20 \%)$ & $6(40 \%)$ & \multirow[t]{5}{*}{0.25} \\
\hline IV & $3(60 \%)$ & $5(33 \%)$ & \\
\hline V & 0 & $2(13 \%)$ & \\
\hline $\mathrm{III}+\mathrm{V}$ & 0 & $2(13 \%)$ & \\
\hline $\mathrm{IV}+\mathrm{V}$ & $1(20 \%)$ & 0 & \\
\hline
\end{tabular}

Table 3 lists the cumulative dose of immunosuppressive therapy received by 20 of the 23 patients that were managed with MMF/MPA upfront. 15 of the 20 patients that received MMF/MPA self-identified as Indigenous Australians. Compared to non-Indigenous Australians, Indigenous Australians received a significantly lower cumulative dose of MMF over the initial 24 weeks $(374.6 \mathrm{~g}$ vs. $255.9 \mathrm{~g}, \mathrm{p}=0.047$ ). The cumulative dosage of prednisolone over the initial 24 weeks and proportion of patients that received pulse methylprednisolone were similar. 
Table 3

- Induction therapy in patients received mycophenolate

\begin{tabular}{|lllll|}
\hline & Total & $\begin{array}{l}\text { Non-Indigenous } \\
\text { Australians }\end{array}$ & $\begin{array}{l}\text { Indigenous } \\
\text { Australians }\end{array}$ & $\begin{array}{l}\text { P- } \\
\text { value }\end{array}$ \\
\hline No. of Patients & 20 & 5 & 15 & \\
\hline Mean Creatinine & $\begin{array}{l}143.0 \\
(+/-22.26)\end{array}$ & $145.6(+/-131.4)$ & $\begin{array}{l}142.1 \\
(+/-92.25)\end{array}$ & 0.947 \\
\hline Mean ACR & $\begin{array}{l}289.71 \\
(+/-70.7)\end{array}$ & $135.6(+/-187.7)$ & $341(+/-338.3)$ & 0.217 \\
\hline Total MMF dose (g, mean +/-SD) & $\begin{array}{l}285 \\
+/-117.57\end{array}$ & $374.6+/-97.4$ & $255.9+/-110.79$ & 0.047 \\
\hline $\begin{array}{l}\text { Total Prednisolone dose (mg, mean } \\
+/-S D)\end{array}$ & $\begin{array}{l}3735 \\
+/-1959\end{array}$ & $3734+/-1674.2$ & $3736+/-2100.3$ & 0.999 \\
\hline $\begin{array}{l}\text { Number of patients received Pulse } \\
\text { methylprednisolone }\end{array}$ & $8(40 \%)$ & $3(60 \%)$ & $5(33 \%)$ & 0.347 \\
\hline \begin{tabular}{l} 
MMF - Mycophenolate mofetil; SD - standard deviation \\
\hline
\end{tabular} & & & \\
\hline
\end{tabular}

Table 4 illustrates the rate of remission at one-year post commencement of mycophenolate induction therapy. While a lower rate of CR was achieved among patients self identify as Indigenous Australians, this was not statistically significant $(40 \%$ vs. $60 \%, p=0.617)$. The combined remission rate was similar between the two groups.

Table 4

Remission rate as per KDIGO criteria

\begin{tabular}{|lllll|}
\hline & Total & Non-Indigenous Australians & Indigenous Australians & P-value \\
\hline No. of Patients & 20 & 5 & 15 & \\
\hline CR & $9(45 \%)$ & $3(60 \%)$ & $6(40 \%)$ & 0.617 \\
\hline CR + PR & $15(75 \%)$ & $4(80 \%)$ & $11(73 \%)$ & 1 \\
\hline
\end{tabular}

The composite outcomes of disease relapse, doubling of creatinine, dialysis dependence and death occurred in 5 of the 15 Indigenous Australian patients. None of the non-Indigenous Australian patients achieved a composite outcome. Table 5 and Fig. 1 demonstrate the composite outcome and the KaplanMeier analysis. 
Table 5

- Composite renal outcome in patients received mycophenolate

\begin{tabular}{|lll|}
\hline & Non-Indigenous Australians & Indigenous Australians \\
\hline Total number & 5 & 15 \\
\hline Death & 0 & 2 \\
\hline Relapse & 0 & 4 \\
\hline Doubling of creatinine & 0 & 5 \\
\hline Dialysis dependence & 0 & 4 \\
\hline Composite & 0 & 5 \\
\hline
\end{tabular}

Table 6 summarised the incidence and incidence rate ratio of infection related hospitalisations and infection related intensive care unit (ICU) admissions over the follow-up period. Overall, 46 episodes of infection related hospitalisations occurred in patients who received mycophenolate. $96 \%$ of the hospitalisation episodes occurred in Indigenous Australians. This equated to a non-statistically significant incidence rate ratio of $3.66(95 \% \mathrm{Cl} 0.89-15.09, \mathrm{p}=0.073)$. The incidence rate of ICU admissions was also not statistically significant, $I R R=1.16(95 \% \mathrm{Cl} 0.14-9.45, \mathrm{p}=0.599)$. Figure 2 illustrates the aetiology of infection observed. Respiratory infectious were the most common infectious seen in Indigenous Australian patients treated with mycophenolate, occurring in 23 of the 44 episodes. This was followed by superficial skin infection, occurring in 16 episodes, and bacteraemia, occurring in 6 episodes. 8 episodes of hospitalisations had more than one site of infection. Notable infections included Nocardia intracranial abscess in one, grade $2 / 3$ crusted scabies in three, and melioid bacteraemia in two. In one case of melioid bacteraemia was complicated with septic shock and multiple hepatic abscesses. 
Table 6

- Incidence of infection related hospitalisations over the follow-up period in patients treated with mycophenolate

\begin{tabular}{|c|c|c|c|c|c|}
\hline & Total & $\begin{array}{l}\text { Non- } \\
\text { Indigenous }\end{array}$ & $\begin{array}{l}\text { Indigenous } \\
\text { Australians }\end{array}$ & IRR (95\% Cl) & $\begin{array}{l}\mathrm{P}- \\
\text { value }\end{array}$ \\
\hline Total number & 20 & 5 & 15 & & \\
\hline Time at risk (ptyr^) & 87.55 & 12.48 & 75.07 & & \\
\hline $\begin{array}{l}\text { Infection related } \\
\text { admissions }\end{array}$ & 46 & $2^{\star}$ & 44 & & \\
\hline Incidence rate (per ptyr) & 0.53 & 0.16 & 0.59 & $\begin{array}{l}3.66(0.89- \\
15.09)\end{array}$ & 0.073 \\
\hline $\begin{array}{l}\text { Infection related ICU } \\
\text { admissions }\end{array}$ & 8 & 1 & 7 & & \\
\hline Incidence rate (per ptyr) & 0.09 & 0.08 & 0.09 & $\begin{array}{l}1.16(0.14- \\
9.45)\end{array}$ & 0.599 \\
\hline
\end{tabular}

\section{Discussion}

This retrospective comparative study adds to our existing knowledge of the induction treatment and outcome of lupus nephritis in Australia. It is, to our knowledge, the first study examining and comparing the differences in outcome between Indigenous Australian and non-Indigenous Australian lupus nephritis patients of Northern Territory.

MMF was the most frequently prescribed initial induction immunosuppressive agents in 20 of the 23 patients. The routine use of mycophenolate as first-line agent for induction therapy is in keeping with recommendations from society guidelines. The American College of Rheumatology, European League Against Rheumatism and Kidney Disease: Improve Global Outcome guidelines recommended the use of MMF/MPA or low dose cyclophosphamide as reasonable first line therapy for induction, ${ }^{4-7}$ with a recommended target dose of 2-3g daily (336-504g cumulative over 24 weeks. Preferential use of MMF/MPA over low-dose cyclophosphamide in our unit was an established practice based on anecdotal evidence suggesting of higher risk of neutropenia and infectious complications associated with cyclophosphamide.

When compared to non-Indigenous Australians, Indigenous Australians were less likely to be in CR at 12 months and had a higher incidence of composite adverse renal outcomes over the follow-up period. The poor rate of CR observed in Indigenous Australians were consistent with those reported in the literature. ${ }^{19,20}$ The reason for the observed poor rate of $C R$ and higher incidence of composite adverse renal outcomes were likely multifactorial. In addition to receiving a lower cumulative dose of MMF over 
induction period, lower socio-economic status, higher prevalence of co-morbid conditions such as diabetes and geographical barrier to healthcare were likely to have all contributed to the observed worse outcome. When compared to non-Indigenous Australians, Indigenous Australians of the Northern Territory were more likely to be residing in remote communities, occupy the lowest quintile of equivalised weekly household income and were less likely to have access to health provider when necessary. ${ }^{21}$ These factors may have also contributed to late presentation of disease, leading to delay in diagnosis and commencement of treatment.

A higher incidence of hospitalisation secondary to infections was observed in Indigenous Australian patients in our study. This is in spite of the routine use of trimethoprim-sulfamethoxazole antimicrobial prophylaxis for melioidosis and Pneumocystis pneumonia in our centre ${ }^{24}$ The higher incidence of infection in immunosuppressed Indigenous Australians was consistent with observations from other comparative studies in Indigenous LN patients and in renal transplant recipients. ${ }^{20,22}$ As an example, Ghazanfari et al. reported infections as the leading cause of mortality in their cohort of Indigenous Australian LN patients, occurring in $38 \%$ of death. ${ }^{23}$ The higher incidence of infection observed in our study may have led to the lower cumulative dose of mycophenolate prescribed to Indigenous Australian patients, whether deliberate or reactionary. Elevated existing background risk of infection including pneumococcal disease, ${ }^{25}$ group A Streptococcus infection, ${ }^{26}$ strongyloidiasis, ${ }^{27}$ and tuberculosis ${ }^{28}$ in Indigenous Australians are known and documented in literature, ${ }^{29}$ and are likely exacerbated by social inequities such as inadequate housing, overcrowding and poverty. ${ }^{30-33}$.

In addition to optimising the cumulative dosage of induction therapy in line with guideline recommendation, strategies aimed at improving LN outcome in Indigenous Australians of Northern Territory may necessitate a system-wide approach aimed at improving disparities in social inequities and barrier to accessing healthcare in order to reduce exposure to background infection risks and diagnostic latency.

Targeted immunosuppressive therapy aimed at suppressing specific pathogenic humoral immunity pathways could an alternative approach to optimize LN outcome. The sparing of the innate immune system and cell-mediated adaptive immunity may potentially limit the risk of infection. The efficacy and safety of intravenous anti-CD20 + B cell depleting antibody rituximab for the induction treatment was previously examined in the LUNAR trial. Despite some promising biochemical results with statistically significant reduction in anti-dsDNA and improvement in complement $\mathrm{C} 3$ and $\mathrm{C} 4$ levels, the trial failed to achieve the primary end point. ${ }^{34}$ Rituximab, since then, had largely been reserved for patients with refractory or relapsed disease. ${ }^{1,4-6}$ The safety and efficacy of rituximab in the Top End of Northern Territory was examined in a retrospective descriptive study examining the off-label use of rituximab in patients with autoimmune diseases. ${ }^{35}$ The authors of the study reported 18 episodes of infection in 66 patients, of whom, $41(62.1 \%)$ self-identified as Indigenous Australians. ${ }^{35} \mathrm{~A}$ 'clinically significant response' was seen in 3 of the 4 patients treated for Lupus Nephritis. Accepting the limitations of retrospective study and the inconsistent documentation of objective disease activity, the authors concluded that off- 
label use of rituximab for treatment of autoimmune diseases is common and safe in majority of cases. Further studies of rituximab for management of LN in the Top End are warranted to support its use as upfront therapy in Indigenous Australians.

The major strength of our study is the unique population examined. To our knowledge, this is the first study examining the treatment and outcome of LN in an Indigenous Australian predominant patient cohort. Despite having a known higher incidence and prevalence of SLE and LN, Indigenous Australians are underrepresented in the existing medical literature. Our study was limited by its retrospective uncontrolled nature of the study design. As data collection was highly reliant on hospital medical records, the lack of information, particularly pertaining to vaccination records makes the adjustment of potential confounders challenging. The relatively small sample size of 23 patients also underpowered our study. A prospective study involving multiple geographical centres with a high Indigenous Australian patient population should be therefore be considered in order to better understand the differences in treatment response between Indigenous Australian and non-Indigenous Australian LN patients.

\section{Conclusion}

We retrospectively reviewed and compared the induction treatment and outcome of all patients with newly diagnosed proliferative LN and/or class V LN with nephrotic range proteinuria. In our cohort of 23 patients, mycophenolate was the most prescribed upfront induction therapy in 20 patients. Indigenous Australian LN patients, when compared to non-Indigenous LN patients, were prescribed a lower cumulative dosage of mycophenolate, had a non-significant lower incidence of CR at 1 year, and a higher incidence of composite renal adverse outcome including relapse, doubling of creatinine, need for longterm renal replacement and death. Indigenous Australian LN patients were also found to have a nonstatistically higher incidence of infection related admissions despite a lower prescribed mycophenolate dose. These results bring in to question the safety and efficacy profile of mycophenolate as induction therapy in Indigenous Australian LN patients. Future studies should examine alternative approaches that minimize infection risk and improve renal outcomes in Indigenous Australian patients.

\section{Abbreviations}

SLE - Systemic lupus erythematosus

LN - Lupus nephritis

RCT - Randomised control trial

LUNAR - Lupus Nephritis Assessment with Rituximab study trial

CR - Complete remission

PR - Partial remission 
MMF - Mycophenolate mofetil

Anti-dsDNA - Anti-double stranded DNA

ISN/RPS - International Society of Nephrology/Renal Pathology Society

ACR - Albumin-creatinine ratio

PCR - Protein-creatinine ratio

MPA - Mycophenolic acid

KDIGO - Kidney disease: improving global outcome

ESKD - End stage kidney disease

Ptyr - Patient-year

ICU - Intensive care unit

\section{Declarations}

\section{Ethics approval and consent to participate}

Ethics approval was obtained from the Human Research Ethics Committees of the Menzies School of Research and the Top End Health Service Research Governance Office, Northern Territory, Australia (Reference number HREC-2020-3869). All research methods were carried out in accordance with the Australian National Health and Medical Research Council (NHMRC) National Statement on Ethical Conduct in Human Research (2007). A waiver of informed consent from individual participants was granted based on the assessment of the Human Research Ethics Committee of the Northern Territory Department of Health and Menzies School of Health Research.

Consent for publication - Not applicable

Availability of data and material - The datasets used and/or analysed during the current study are available from the corresponding author on reasonable request.

Competing interest - The authors of the report declare there is no affiliation with companies that has a financial interest and there is no conflict of interest to declare.

Funding - The authors of the study received no funding during the duration of the study

Acknowledgement - The authors would like to acknowledge the patients and clinicians of the Department of Renal Medicine for their collaborative contribution to the study. 
Author's contribution - CX was involved in the collection of data, its analysis, the writing of manuscript and its editing, KLG was involved extensively in the collection of data, AA was involved in the collection of data and editing of manuscript, KP was involved in the conception of study and extensively involved in the final editing of manuscript.

\section{References}

1. Parikh S V., Almaani S, Brodsky S, Rovin BH. Update on Lupus Nephritis: Core Curriculum 2020. Am J Kidney Dis. 2020;76(2):265-281. doi:10.1053/j.ajkd.2019.10.017

2. Danchenko N, Satia JA, Anthony MS. Epidemiology of systemic lupus erythematosus: A comparison of worldwide disease burden. Lupus. 2006;15(5):308-318. doi:10.1191/0961203306lu2305xx

3. Bajema IM, Wilhelmus S, Alpers CE, et al. Revision of the International Society of Nephrology/Renal Pathology Society classification for lupus nephritis: clarification of definitions, and modified National Institutes of Health activity and chronicity indices. Kidney Int. 2018;93(4):789-796. doi:10.1016/j.kint.2017.11.023

4. Hahn BH, McMahon MA, Wilkinson A, et al. American College of Rheumatology guidelines for screening, treatment, and management of lupus nephritis. Arthritis Care I\& Res. 2012;64(6):797-808. doi:https://doi.org/10.1002/acr.21664

5. Fanouriakis A, Kostopoulou M, Cheema K, et al. 2019 Update of the Joint European League Against Rheumatism and European Renal Association-European Dialysis and Transplant Association (EULAR/ERA-EDTA) recommendations for the management of lupus nephritis. Ann Rheum Dis. 2020;79(6):713 LP - 723. doi:10.1136/annrheumdis-2020-216924

6. Cattran DC, Feehally J, Cook HT, et al. Kidney disease: Improving global outcomes (KDIGO) glomerulonephritis work group. KDIGO clinical practice guideline for glomerulonephritis. Kidney Int Suppl. 2012;2(2):139-274. doi:10.1038/kisup.2012.9

7. Disease R, Rheum A, Rheumatology C. KDIGO GN Guideline update - Evidence summary Lupus nephritis Antimalarial therapy for lupus nephritis. 2018:1-7.

8. Mok CC, Yap DYH, Navarra S V, et al. Overview of lupus nephritis management guidelines and perspective from Asia. Int J Rheum Dis. 2013;16(6):625-636. doi:https://doi.org/10.1111/1756$185 X .12212$

9. Austin HA, Klippel JH, Balow JE, et al. Therapy of lupus nephritis. Controlled trial of prednisone and cytotoxic drugs. N Engl J Med. 1986. doi:10.1056/NEJM198603063141004

10. Appel GB, Contreras G, Dooley MA, et al. Mycophenolate mofetil versus cyclophosphamide for induction treatment of lupus nephritis. J Am Soc Nephrol. 2009. doi:10.1681/ASN.2008101028

11. Houssiau FA, Vasconcelos C, D'Cruz D, et al. Immunosuppressive therapy in lupus nephritis: The Euro-Lupus Nephritis Trial, a randomized trial of low-dose versus high-dose intravenous cyclophosphamide. Arthritis I\& Rheum. 2002;46(8):2121-2131. doi:https://doi.org/10.1002/art.10461 
12. Anstey NM, Bastian I, Dunckley H, Currie BJ. Systemic lupus erythematosus in Australian Aborigines: high prevalence, morbidity and mortality. Aust N Z J Med. 1993;23(6):646-651. doi:10.1111/j.14455994.1993.tb04720.x

13. Segasothy M, Phillips PA. Systemic lupus erythematosus in Aborigines and Caucasians in central Australia: A comparative study. Lupus. 2001;10(6):439-444. doi:10.1191/096120301678646191

14. Bossingham D. Systemic lupus erythematosus in the far north of Queensland. Lupus. 2003;12(4):327-331. doi:10.1191/0961203303lu381xx

15. GRENNAN DM, BOSSINGHAM D. Systemic lupus erythematosus (SLE): different prevalences in different populations of Australian Aboriginals. Aust N Z J Med. 1995;25(2):182-183. doi:10.1111/j.1445-5994.1995.tb02843.x

16. Vincent FB, Bourke P, Morand EF, Mackay F, Bossingham D. Focus on systemic lupus erythematosus in Indigenous Australians: Towards a better understanding of autoimmune diseases. Intern Med J. 2013;43(3):227-234. doi:10.1111/imj.12039

17. Mason JA, Bossingham D. The clinical characterisation of systemic lupus erythematosus in a Far North Queensland Indigenous kindred. Lupus. 2009;18(2):144-148.

doi:10.1177/0961203308094997

18. Department of Health NG. 2019-2020 Department of Health Annual Report. 2020. https://digitallibrary.health.nt.gov.au/prodjspui/handle/10137/11485. Accessed July 8, 2021.

19. Nigam A, Baer R, Green S, Neuen BL, Vile A, Mantha M. Lupus nephritis in Indigenous Australians: a single-centre study. Intern Med J. 2020;50(7):830-837. doi:https://doi.org/10.1111/imj.14710

20. Ghazanfari F, Jabbar Z, Nossent J. Renal histology in Indigenous Australians with lupus nephritis. Int J Rheum Dis. 2018;21(1):194-199. doi:10.1111/1756-185X.13147

21. Australian Institute of Health and Welfare. Aboriginal-and-Torres-Strait-Islander-Health-PerformanceFramework-2017-report-Northern-Territory. 2017.

22. Boan $P$, Swaminathan $R$, Irish $A$. Infectious complications in indigenous renal transplant recipients in Western Australia. Intern Med J. 2017. doi:10.1111/imj.13450

23. Ghazanfari F, Jabbar Z, Nossent J. Renal histology in Indigenous Australians with lupus nephritis. Int J Rheum Dis. 2018;21(1):194-199. doi:https://doi.org/10.1111/1756-185X.13147

24. Majoni SW, Hughes JT, Heron B, Currie BJ. Trimethoprim + Sulfamethoxazole Reduces Rates of Melioidosis in High-Risk Hemodialysis Patients. Kidney Int reports. 2017;3(1):160-167. doi:10.1016/j.ekir.2017.09.005

25. Meder KN, Jayasinghe S, Beard F, et al. Long-term impact of pneumococcal conjugate vaccines on invasive disease and pneumonia hospitalizations in indigenous and non-indigenous Australians. Clin Infect Dis. 2020;70(12):2607-2615. doi:10.1093/cid/ciz731

26. May PJ, Bowen AC, Carapetis JR. The inequitable burden of group a streptococcal diseases in indigenous Australians: We need to fill evidence gaps and make clinical advances to reduce these diseases of disadvantage. Med J Aust. 2016;205(5):201-204. doi:10.5694/mja16.00400 
27. Johnston FH, Morris PS, Speare R, et al. Strongyloidiasis: A review of the evidence for Australian practitioners. Aust J Rural Health. 2005;13(4):247-254. doi:https://doi.org/10.1111/j.14401584.2005.00710.x

28. Bright A, Denholm J, Coulter C, Waring J, Stapledon R. Tuberculosis notifications in Australia, 20152018. Commun Dis Intell. 2020;44:2015-2018. doi:10.33321/cdi.2020.44.88

29. Ioannides S, Beard F, Larter N, et al. Vaccine Preventable Diseases and Vaccination Coverage in Aboriginal and Torres Strait Islander People, Australia, 2011-2015. Commun Dis Intell. 2019;43:2011-2015. doi:10.33321/cdi.2019.43.36

30. Tong SYC, McDonald MI, Holt DC, Currie BJ. Global implications of the emergence of communityassociated methicillin-resistant Staphylococcus aureus in Indigenous populations. Clin Infect Dis an Off Publ Infect Dis Soc Am. 2008;46(12):1871-1878. doi:10.1086/588301

31. Bailie RS, Stevens MR, McDonald E, et al. Skin infection, housing and social circumstances in children living in remote Indigenous communities: testing conceptual and methodological approaches. BMC Public Health. 2005;5:128. doi:10.1186/1471-2458-5-128

32. Davidson L, Knight J, Bowen AC. Skin infections in Australian Aboriginal children: a narrative review. Med J Aust. 2020;212(5):231-237. doi:10.5694/mja2.50361

33. Colosia AD, Masaquel A, Hall CB, Barrett AM, Mahadevia PJ, Yogev R. Residential crowding and severe respiratory syncytial virus disease among infants and young children: a systematic literature review. BMC Infect Dis. 2012;12:95. doi:10.1186/1471-2334-12-95

34. Rovin BH, Furie R, Latinis K, et al. Efficacy and safety of rituximab in patients with active proliferative lupus nephritis: The lupus nephritis assessment with rituximab study. Arthritis I\& Rheum. 2012;64(4):1215-1226. doi:https://doi.org/10.1002/art.34359

35. Wongseelashote S, Tayal V, Bourke PF. Off-label use of rituximab in autoimmune disease in the Top End of the Northern Territory, 2008-2016. Intern Med J. 2018;48(2):165-172. doi:10.1111/imj.13554

\section{Figures}




\section{Composite Renal Outcome}

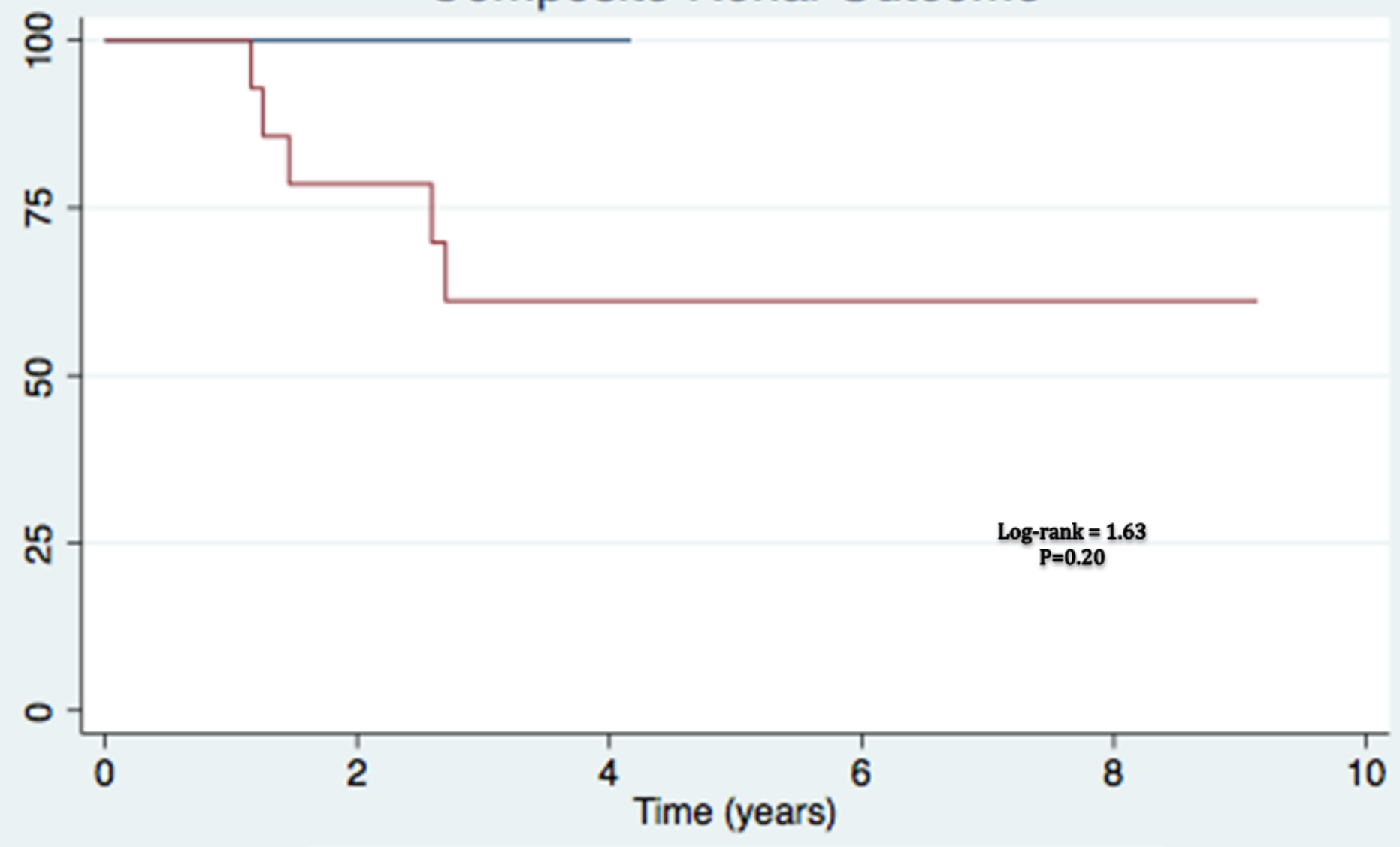

Non-Indigenous

Indigenous

Figure 1

Kaplan-Meier analysis of composite renal outcome in patients received Mycophenolate
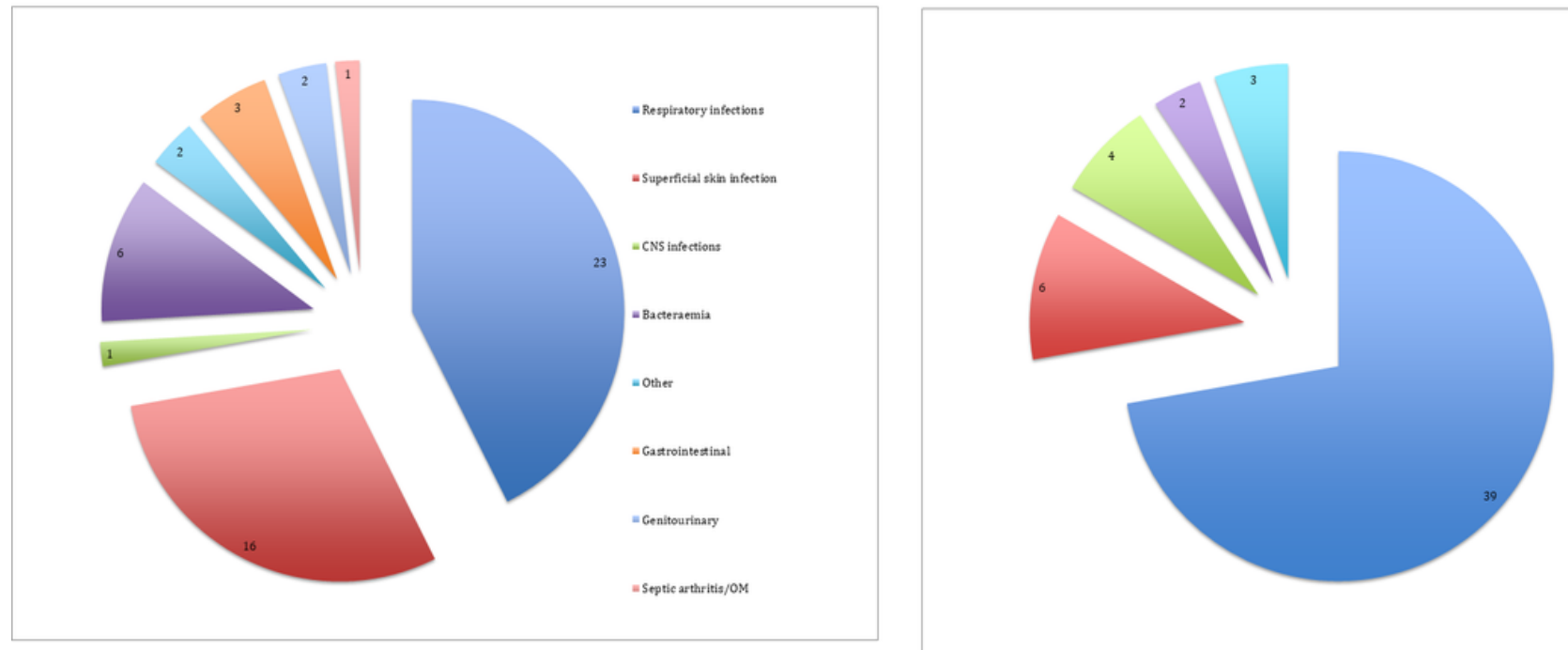
Aetiology of infections organ system (Top) and organisms (Bottom) 